\title{
Diffusion tensor imaging differences relate to memory deficits in diffuse traumatic brain injury
}

\author{
Eva M Palacios ${ }^{1,2}$, Davinia Fernandez-Espejo ${ }^{1,2}$, Carme Junque ${ }^{1,2^{*}}$, Rocio Sanchez-Carrion ${ }^{3}$, Teresa Roig ${ }^{3}$, \\ Jose M Tormos ${ }^{3}$, Nuria Bargallo ${ }^{4}$, Pere Vendrell ${ }^{1,2}$
}

\begin{abstract}
Background: Memory is one of the most impaired functions after traumatic brain injury (TBI). We used diffusion tensor imaging (DTI) to determine the structural basis of memory deficit. We correlated fractional anisotropy (FA) of the fasciculi connecting the main cerebral regions that are involved in declarative and working memory functions.

Methods: Fifteen patients with severe and diffuse TBI and sixteen healthy controls matched by age and years of education were scanned. The neuropsychological assessment included: Letter-number sequencing test (LNS), 2back task, digit span (forwards and backwards) and the Rivermead profilet. DTI was analyzed by a tract-based spatial statics (TBSS) approach.

Results: Whole brain DTI analysis showed a global decrease in FA values that correlated with the 2-back d-prime index, but not with the Rivermead profile. $\mathrm{ROI}$ analysis revealed positive correlations between working memory performance assessed by 2-back d-prime and superior longitudinal fasciculi, corpus callosum, arcuate fasciculi and fornix. Declarative memory assessed by the Rivermead profile scores correlated with the fornix and the corpus callosum.
\end{abstract}

Conclusions: Diffuse TBI is associated with a general decrease of white matter integrity. Nevertheless deficits in specific memory domains are related to different patterns of white matter damage.

\section{Background}

Diffuse axonal injury (DAI) was initially defined as widespread damage to axons throughout the white matter, evoked by intense shear and strain forces resulting from rapid acceleration and deceleration of the brain with or without impact after traumatic brain injury (TBI) [1,2]. More recently, traumatic axonal injury (TAI) has been suggested as a more appropriate term for describing axonal damage because it encompasses not only the primary axonal damage specifically caused by shear/strain injury, but also secondary alterations of white matter such as metabolic, hypoxic and microvascular damage or excitotoxicity $[3,4]$.

Although TAI has been described in neuropathological terms, magnetic resonance imaging (MRI) allows the detection of microhemorrhages and other indirect signs in regions commonly affected by this injury such as the

\footnotetext{
* Correspondence: cjunque@ub.edu

'Department of Psychiatry and Clinical Psychobiology, University of Barcelona, Barcelona, Spain

Full list of author information is available at the end of the article
}

subcortical white matter, the corpus callosum and the dorsolateral quadrant of the rostral brain-stem. It has recently been demonstrated that $\mathrm{T} 2 \%$-weighted MRI at high field strength is a useful tool for the identification of traumatic microbleeds even in the chronic stage of TBI [5]. However, diffusion tensor imaging (DTI) has been suggested as the best technique for the detection of subtle white matter changes [6] given that it can reveal significant abnormalities in white matter in patients with normal findings in conventional MRI $[7,8]$.

DTI is a non-invasive MRI technique that identifies the microscopic physical properties of tissues directly through the observation of translational molecular movement of water [9]. Water diffusion in cerebral white matter tends to be anisotropic, because the highly linear organization of white matter fibers restricts movement in other directions $[10,11]$. Fractional anisotropy (FA), one of the main DTI-derived indices, provides information of the degree of directionality of water diffusion and on microstructural white matter changes. DTI has been shown to be an efficient technique for 
determining white-matter integrity in several pathologies [12]. It has also been proposed as the most feasible biomarker of TAI and one of the best indicators of TBI severity $[13,14]$. Reductions in FA have been detected not only in moderate and severe TBI patients [15-18] but also in cases of mild TBI [19-24]. Moreover, DTI has proved to be an excellent tool for evaluating structural changes after TBI in longitudinal studies [16-18].

The advantages of DTI have resulted in a growing body of scientific evidence regarding the relationship between white matter damage and neuropsychological deficits in TBI. Studies conducted with pediatric samples have identified correlations between FA values and various cognitive functions, including cognitive processing speed and interference, executive functioning, IQ, verbal working memory, reading comprehension and letter naming speed [25-27]. Recently, Wu et al., [28] reported correlations between immediate recall and left cingulum bundles in adolescents after mild TBI. Some studies have related FA measurements with neuropsychological deficits in adults. Nakayama et al. [29] identified a positive correlation between the Mini-Mental State Examination (MMSE) and FA in the splenium of the corpus callosum. Salmond et al. [30] found a significant correlation between diffusivity and the impairment of learning and memory in the posterior cingulate, hippocampal formation and cortical areas. Kraus et al. [31] in a sample including all grade severities, found reduced FA in the ROIs analyzed and obtained a measure of the total regions of reduced FA that negatively correlated with the three cognitive domains evaluated. Furthermore, in a mild TBI sample, Niogi et al. [32] found a significant correlation between attentional control and FA within a $\mathrm{ROI}$ in the corona radiata and between memory performance and FA in the ROI placed in the uncinate both in the group of mild TBI patients and the control group. Kumar et al. [18] found correlations between the corpus callosum and neuropsychological tests involving processing speed as well as visuospatial and visuperceptive tasks. Finally, Lipton et al., [33] and Miles et al. [34] found that reductions in FA in dorsolateral prefrontal cortex correlated significantly with tests of executive functions. In summary, DTI technique, in special FA measures, has been found sensitive to reflect cognitive deficits associate with TBI.

Memory is one of the functions that is most frequently impaired by TBI [35-37]. The concept of multiple memory systems and their different neuroanatomical substrates is currently accepted [38,39]. Declarative and working memory systems are significantly impaired after traumatic brain injury (TBI). Deficits in declarative memory - the capacity for conscious recollection of facts and events - are a common consequence of head trauma that are disproportionately suffered in comparison with other cognitive functions $[35,40]$. These memory difficulties improve slowly and although progress is made over the first and second year following injury, they remain apparent over time [40-42]. Neuroanatomically, declarative memory depends on the integrity of the hippocampus and its connections with the neocortex $[43,44]$. In neuroimaging studies with TBI patients, declarative memory has been found to correlate negatively with hippocampal $[45,46]$ and fornix damage [47]. Working memory is defined as the ability to maintain and manipulate information temporarily [48]. Impairment of this memory is frequent in TBI patients given that implicated neural substrates, particularly the frontal cortex, are highly vulnerable in this type of injury. There is considerable evidence that working memory depends on network activity including the frontal and parietal regions and its connections. A meta-analysis of functional neuroimaging studies conducted by Owen et al. [49] provided strong evidence for the activation of frontal and parietal cortical regions by various versions of the $n$-back paradigm. The main fasciculus linking the parietal and frontal lobes is the superior longitudinal fasciculus (SLF) and hence it is likely that this has a role in working memory. Relations between the SLF and working memory deficits have been reported in multiple sclerosis [50] but not in TBI patients. To our knowledge there is no study investigating the impairment of white matter damage related to declarative and working memory deficits in a sample of severe and diffuse TBI.

The aim of this study was to investigate the role of white matter damage in declarative and working memory deficits after diffuse TBI, focusing on the main associative fasciculi [51] including those connecting the cerebral regions involved in the declarative memory and working memory networks.

Our study had two main hypotheses: firstly, that a decreased FA in the superior longitudinal fasciculi (SLF), which is presumably involved in working memory function since it links the parietal and prefrontal regions, would correlate with working memory deficits, and, secondly, that a decreased FA in the fornix, the main fasciculus interconnecting the hippocampus with the frontal lobe, would correlate with declarative memory impairment.

\section{Methods}

\section{Subjects}

A cross-sectional study of thirty-one subjects was performed. Fifteen patients (eleven male) with severe TBI were recruited from the Head Injury Unit of the Institut de Neurorehabilitació Guttmann. Inclusion criteria were: a) age $<40$ years, b) diffuse axonal injury according to clinical MRI without focal cortical lesions or larger than $1.5 \mathrm{~cm} 3, \mathrm{c})$ severe TBI: defined as a minimal Glasgow 
Coma Scale (GCS) score $\leq 8$ assessed at the first contact with the emergency services, d) emergence from posttraumatic amnesia (PTA) phase at the moment of the enrollment according to the Galveston Orientation and Attention Test (GOAT) [52], defined as two consecutive scores > 65, and f) no previous history of TBI, drug intake, neurological, or psychiatric disorders.

The etiology of TBI was a traffic accident in all cases. Fourteen patients were involved in car collisions, and one was a pedestrian hit by a motor vehicle. All patients had closed head injury and had not received surgery for extra- or subdural hematoma; all structural MRI scans were suggestive of TAI. The neuroradiologist (NB) took into account T1-weighted, FLAIR, and T2* GE sequences. The $\mathrm{T} 2 *$ GE sequences, which have a high level of sensitivity for detecting chronic hemosiderin, indicated evidence of TAI-related neuropathology. The method proposed by Gennarelli et al. [2] was used to classify the patients' TAI type. The grading system used was: type I, TAI only involving convexity gray-white matter junction; type II, also involving the corpus callosum in addition to the gray-white junction; and, type III, involving the rostral brainstem as well as the two previous criteria. Cases in which the midbrain was involved, but no corpus callosum lesions were apparent, were classified as type III (see Table 1).

A control group of sixteen healthy subjects (nine male) were recruited from relatives and friends of the TBI group. This control group was matched by age, years of education and premorbid intellectual function estimated using the Vocabulary subtest of the Wechsler Adult Intelligence Scale (WAIS-III) [53], recognized as an efficient method for estimating general intelligence [54] (see Table 2). All subjects were right-handed, Caucasian-Mediterranean, and none had a previous history of neurological or psychiatric diseases.

The study was approved by the Ethical and Research Committee of the Institut Universitari de Neurorehabilitacio Guttmann and all participants gave written informed consent.

\section{Memory assessment}

Working memory was evaluated by the Digit span and Letter-Number Sequencing (LNS) subtests of the WAISIII [53] and a visual 2-back task [55]. Digit span was measured as the series length correctly reproduced at least once in the same order (forwards) and in reverse order (backwards). In the LNS, subjects heard lists of randomized numbers and letters (in alternating order) of increasing lengths, and were asked to reproduce the numbers and letters beginning with the lowest in each series, always with numbers first. The scores from the LNS were calculated by adding all correct items. In the 2-back task, numbers appeared on the screen for
$500 \mathrm{~ms}$ against a black background, followed by a fixation cross for $1500 \mathrm{~ms}$. The subjects were asked to decide whether the number they were looking at matched the one that they had seen two numbers earlier in the sequence. The numbers of correct responses as well as the reaction time were recorded. The d-prime index, a bias-free measure that takes both correct answers and errors into account, was also calculated to determine the accuracy of performance.

The Rivermead Behavioural Memory Test (RBMT) [56] was selected for its ability to explore declarative memory, and its ecological validity in assessing TBI patients. This test consists of 11 subtests including the following: remembering a name, a hidden belonging and an appointment; recognizing pictures and faces; recalling a prose passage; remembering a short route; remembering to deliver a message; and knowledge of some basic information such as the date, place and time. Those are designed as analogs of everyday tasks, reflecting the kinds of situations with which patients typically experience difficulty on a day-to-day basis. Two methods of standardizing scores across subtests allow for derivation of either a screening score, with subtest raw scores categorized on a scale of $0 \pm 1$ (maximum score 12 points), or a standardized profile score, with subtest raw scores categorized on a scale of $0 \pm 2$ (maximum score 24 points). The slightly more fine-grained standardized profile score provides a more sensitive analysis of performance [57] thus we use this score for our correlation analysis.

\section{Image acquisition and analysis}

MRI data sets were acquired on a 1.5 T Signa GE (General Electric, Milwaukee, WI) at the Centre de Diagnostic per la Imatge of the Hospital Clínic (CDIC), Barcelona. Diffusion weighted images were sensitized in 25 non-collinear directions with a b-value $=1000 \mathrm{sec} /$ $\mathrm{mm}^{2}$, using an echo-planar (EPI) sequence $(\mathrm{TR}=$ $9999.996 \mathrm{~ms}, \mathrm{TE}=85 \mathrm{~ms}, 20$ axial slices with a resolution of $0.9375 \times 0.9375 \mathrm{~mm}$, slice thickness $=5 \mathrm{~mm}$, gap $=2 \mathrm{~mm}$ matrix size $=128 \times 128, \mathrm{FOV}=100$ ).

Data preprocessing and analysis was performed using FMRIB's software library [FSL version 4.1; Oxford Centre for Functional MRI of the Brain (FMRIB), UK; http://www.fmrib.ox.ac.uk/fsl/]. Image artefacts due to eddy current distortions were minimized by registering the diffusion images to the b0 images. The registered images were skull-stripped using the Brain Extraction Tool (BET) [58]. Fractional anisotropy maps were calculated using the FMRIB's Diffusion Toolbox v.2.0 [FDT, [59]]. After calculation of the FA map for each subject, we implemented a voxel-wise statistical analysis of the FA data using Tract-Based Spatial Statistics v1.2 (TBSS) which aims to overcome the limitations of 
Table 1 Clinical and neuroimaging characteristics of the TBI group

\begin{tabular}{|c|c|c|c|c|c|c|}
\hline PT & GCS & PTA & Initial CT & MRI findings (T2*/FLAIR-Hemosiderin deposits) & tevol & TAI \\
\hline 1 & 8 & 150 & SAH. Small hemorrhage in $L$ thalamus & Microbleeds in L thalamus, $R$ caudate, midbrain, frontal lobe, and CC & 207 & III \\
\hline 2 & 7 & 60 & SAH. Small hemorrhagic lesion at the uncus & $\begin{array}{l}\text { Microbleeds in R caudate, thalamus, pons, frontoparietal lobes and } \\
\text { CC }\end{array}$ & 285 & III \\
\hline 3 & 3 & 125 & $\begin{array}{l}\text { Small frontobasal contusion and bilateral } \\
\text { hemorrhagic foci in } \mathrm{R} \text { frontal lobe and } \mathrm{R} \\
\text { thalamus }\end{array}$ & $\begin{array}{l}\text { Microbleeds in } R \text { thalamus, } R \text { fronto-temporo parietal lobes, } \\
\text { hippocampus and CC. Frontobasal contusion }(<1.5 \mathrm{~cm})\end{array}$ & 315 & $\|$ \\
\hline 4 & 5 & 45 & No evidence of lesions & Microbleeds in dorsal midbrain and $L$ frontal lobe & 429 & III \\
\hline 5 & 4 & 40 & $\begin{array}{l}\text { SAH. Hemorrhagic focus in } L \text { frontal white } \\
\text { matter }\end{array}$ & $\begin{array}{l}\text { Microbleeds in midbrain, R/L hippocampus, frontal and temporal } \\
\text { lobes, and CC }\end{array}$ & 550 & III \\
\hline 6 & 7 & 51 & $\begin{array}{l}\text { SAH. Hemorrhagic focus in the } R \text { frontal white } \\
\text { matter, and R intraventricular hemorrhage }\end{array}$ & Microbleeds in R/L hippocampus and $\mathrm{R}$ prefrontal region & 146 & I \\
\hline 7 & 4 & 45 & Hyperdense lesion in the $L$ medial temporal lobe & $\begin{array}{l}\text { Microbleeds in } L \text { caudate, } R / L \text { hippocampus, midbrain, } L \text { parietal, } R \\
\text { frontal lobes and } C C\end{array}$ & 165 & III \\
\hline 8 & 4 & 75 & $\begin{array}{l}\text { Multiple small bilateral subcortical hemorrhagic } \\
\text { foci }\end{array}$ & $\begin{array}{l}\text { Microbleeds in } L \text { thalamus, } R \text { midbrain, cerebellar peduncle, } R / L \\
\text { frontal parietal and occipital lobes, } R \text { temporal and CC. Fonto- } \\
\text { temporal deep white matter hyperintensities due to demyelination }\end{array}$ & 86 & III \\
\hline 9 & 3 & 70 & $\begin{array}{l}\text { Small hemorrhagic foci at R internal capsular and } \\
\text { temporal region, and LCC. Intraventricular } \\
\text { hemorrhage }\end{array}$ & $\begin{array}{l}\text { Microbleeds in midbrain, cerebellum, R hippocampus, R internal } \\
\text { capsule and thalamus, L fronto-parietal, and CC }\end{array}$ & 443 & III \\
\hline 10 & 3 & 60 & SAH. Diffuse white matter alterations & $\begin{array}{l}\text { Microbleeds in } R \text { thalamus, } R \text { midbrain, cerebellum, } R / L \text { frontal and } \\
\text { CC. Parietal deep white matter hyperintensities due to } \\
\text { demyelination. }\end{array}$ & 114 & III \\
\hline 11 & 7 & 120 & $\begin{array}{l}\text { Multiple puntiform hemorrhagic foci in both } \\
\text { hemispheres }\end{array}$ & $\begin{array}{l}\text { Microbleeds in } L \text { thalamus, } R \text { globus pallidus, } R / L \text { insula, } R \text { midbrain } \\
R / L \text { frontal, parietal and temporal lobes and } C C\end{array}$ & 306 & III \\
\hline 12 & 4 & 171 & $\begin{array}{l}\text { Puntiform temporal contusion. L temporal } \\
\text { subdural hematoma }\end{array}$ & $\begin{array}{l}\text { Multiple subcortical microbleeds in pyramidal tract, centrum } \\
\text { semiovale, pons, and CC. Deep white matter lesions. } L \text { temporal } \\
\text { contusion }(<1 \mathrm{~cm})\end{array}$ & 213 & III \\
\hline 13 & 8 & 20 & No evidence of lesions & $\begin{array}{l}\text { Microbleeds in } L \text { insula, } R \text { frontal lobe and CC. Deep white matter } \\
\text { lesions predominantly in the parietal lobe }\end{array}$ & 115 & $\|$ \\
\hline 14 & 4 & 105 & Multiple hemorrhagic foci & $\begin{array}{l}\text { Microbleeds in midbrain, fronto-parieto-occipital lobes and CC. Deep } \\
\text { frontal white matter hyperintensities due to demyelination }\end{array}$ & 143 & III \\
\hline 15 & 6 & 120 & $\begin{array}{l}\text { Microhemorrhages in the } L \text { cerebellar } \\
\text { hemisphere and } R \text { frontal lobe }\end{array}$ & $\begin{array}{l}\text { Microbleeds in } R \text { thalamus, } R \text { temporal lobe and in fronto-parietal } \\
\text { lobes. Contusion in } R \text { frontal gyrus and frontobasal }(<1.2 \mathrm{~cm})\end{array}$ & 660 & $\|$ \\
\hline
\end{tabular}

PT: Patient; GCS: Glasgow coma scale; PTA: posttraumatic amnesia; CT: computer tomography; MRI: magnetic resonance imaging; tevol: time of evolution since accident to the MRI evaluation; TAl: diffuse axonal injury; R/L: right/left; CC: corpus callosum; SHA: subarachnoidal hemorrhage.

the standard VBM-style analyses [60], particularly those regarding to its dependence on the goodness of the registration algorithm and on the choice of the spatial smoothing [61]. FA data were aligned into a common space using a non-linear registration algorithm (FNIRT) to register the images to the standard FMRIB58 FA template, which is in MNI152 standard space. Aligned FA maps were visually inspected after

Table 2 Demographic and clinical characteristics of TBI and control groups

\begin{tabular}{lcccc}
\hline & $\begin{array}{c}\text { TBI } \\
\text { group } \\
\text { Mean }\end{array}$ & $\begin{array}{c}\text { SD } \\
\text { Sange) }\end{array}$ & $\begin{array}{c}\text { Control } \\
\text { group } \\
\text { Mean }\end{array}$ & $\begin{array}{c}\text { SD } \\
\text { (Range) }\end{array}$ \\
\hline Age & 23.6 & $4.79(18-32)$ & 23.7 & $4.8(18-32)$ \\
Education (years) & 11.3 & $2.7(8-16)$ & 11.9 & $2.8(8-16)$ \\
$\begin{array}{l}\text { Vocabulary (WAIS- } \\
\text { III) }\end{array}$ & 9.9 & $2.0(8-14)$ & 10.3 & $1.9(8-14)$ \\
\hline
\end{tabular}

$\mathrm{TBI}=$ traumatic brain injury. registration and we confirmed that the result of the previous step was correct. Next, a mean FA image was created from the images from all the subjects in this common space and narrowed to generate a mean FA skeleton that represented the center of all tracts common to the entire group. This was thresholded to FA 0.2 to include the major white matter pathways but to exclude peripheral tracts where there was significant inter-subject variability and partial volume effects with gray matter. This ensured that each subject's skeleton was in the group space while also representing the center of the subject's unique white matter bundles. The aligned FA image for each subject was then projected onto the skeleton by filling the skeleton with FA values from the nearest relevant tract centre. This is achieved for each skeleton voxel by searching perpendicular to the local skeleton structure for the maximum value in the FA image of the subject. The resulting skeletonised data was then fed into voxelwise cross-subject statistics. 


\section{Statistical analysis}

Group comparisons and correlations with neuropsychological measures were performed using Randomise v2.1 from FSL $[62,63]$. As seen in table one, the time of evolution since injury was very heterogeneous. In order to control possible effects of this variable in the correlation results, time of evolution was entered as a non-interest variable in the matrix. The statistical threshold was set at $\mathrm{p}<0.05$ Family Wise Error (FWE) corrected, which is a conservative procedure that allows a high control of Type I error, being the probability of one or more false positives the same as the significance level. The Threshold-Free Cluster Enhancement (TFCE) method was used to define the clusters [64]. Correlation analyses were performed with the 2-back d-prime index and the Rivermead profile score using a region of interest (ROI) approach in the following associative fasciculi: corpus callosum, superior and inferior longitudinal, inferior fronto-occipital, uncinate, and cingulate as well as the fornix and arcuate fasciculi as the major pathways that connect associative cortical regions involved in working and declarative memory. ROI masks were obtained from the Jülich histological atlas $[65,66]$ and the JHU whitematter tractography atlas [67-69]. Areas corresponding to significant clusters were identified using the JHU white-matter tractography atlas. Mean FA values were obtained from each subject's FA skeleton map and skeletonised SLF and fornix ROIs. Mean FA values were obtained from each subject's FA skeleton map and skeletonized for all the fasciculi ROIs mentioned above.

Statistical tests on non-imaging data were performed using SPSS (Statistical Package for the Social Sciences) v.16 (SPSS Inc., Chicago Illinois). Group differences were examined using the Student t-test, since the data were normally distributed using a significance level of $\mathrm{p}<0.05$.

Partial correlation coefficients, controlling for the time of evolution, were used to explore the association between mean FA values and clinical variables and neuropsychological measures. Statistical significance was set at a two-tailed $\mathrm{p} \leq 0.05$.

\section{Results}

\section{Comparison between TBI patients and controls}

Performance on the memory tests is described in Table 3. Statistical significance was obtained for the difference in scores in the LNS subtest (WAIS-III), d-prime index for the 2-back, and the RBMT profile. Forward and backward digits did not reach statistical significance.

Group comparison for FA skeleton maps revealed multiple areas of significant FA reductions in TBI patients as compared to controls. All the long associative fibers were affected, including the corpus callosum,
Table 3 Neuropsychological performance for TBI and control groups

\begin{tabular}{lccccc}
\hline & TBI & group & Control & group & t (p values) \\
& Mean & SD & Mean & SD & \\
\hline Digit forwards & 6.1 & 1.0 & 6.6 & 1.1 & $-1.1(\mathrm{~ns})$ \\
Digit backwards & 4.3 & 1.1 & 4.9 & 0.9 & $-1.6(\mathrm{~ns})$ \\
LNS & 8.6 & 2.7 & 11.0 & 2.8 & $-2.4(0.02)$ \\
2- back (d-prime) & 2.7 & 1.0 & 3.4 & 0.4 & $-2.6(0.01)$ \\
Goals 2-back & 81.4 & 18.3 & 95.2 & 4.8 & $-2.7(0.01)$ \\
Reaction time 2-back & 693.4 & 200.0 & 475.7 & 88.9 & $3.7(0.002)$ \\
(ms) & & & & & \\
RBMT (profile) & 18.1 & 3.4 & 22.6 & 1.3 & $-4.85(0.001)$ \\
\hline
\end{tabular}

TBI: traumatic brain injury; Letter-Number Sequencing (WAIS-III); Goals: number of targets correctly identified; RBMT: Rivermead Behavioral Memory Test; ns: not significant.

the superior and inferior longitudinal fasciculi, and the inferior fronto-occipital fasciculi. Decreased FA was also observed in shorter fibers such as the uncinate fasciculus, cingulum, fornix and anterior thalamic radiation (Figure 1, Table 4). FA was not increased in the TBI group in any cerebral region.

We obtained mean FA values of the whole skeletonized brain and all of the selected ROIs. Group comparisons for all these values reached statistical significance in all cases with $\mathrm{p}<0.001$ (Table 4).

\section{Correlation analysis}

\section{Correlation with clinical variables}

We observed significant negative correlations between FA and posttraumatic amnesia (PTA) in almost all the regions that showed significant FA decreases in the group analysis. Quantitative global mean FA values also showed a high correlation with this variable $(r=-0.903 \mathrm{p}<0.001)$. However, no significant correlations were found in the FA maps analysis for the GCS ( $r=0.206, \mathrm{p}=0.499)$.

\section{Correlation with declarative and working memory}

\section{performance}

The mean global FA measure correlated significantly with 2-back d-prime index $(r=0.584, \mathrm{p}=0.028)$. The correlation of global FA with the RBMT profile score did not reach statistical significance.

The ROI procedure revealed a positive correlation between working memory performance assessed by the 2-back d- index and the FA skeletonized SLF, fornix, and corpus callosum ROIs (Figure 2, Table 5). 2-back dprime index also correlated with the arcuate fascicle (Table 5). Declarative memory performance, assessed by RBMT, correlated with the fornix and the posterior part of the corpus callosum ROIs (Figure 3, Table 5).

No other correlation reached statistical significance in the TBI group. There were no significant correlations between FA and neuropsychological measures in the control group. 


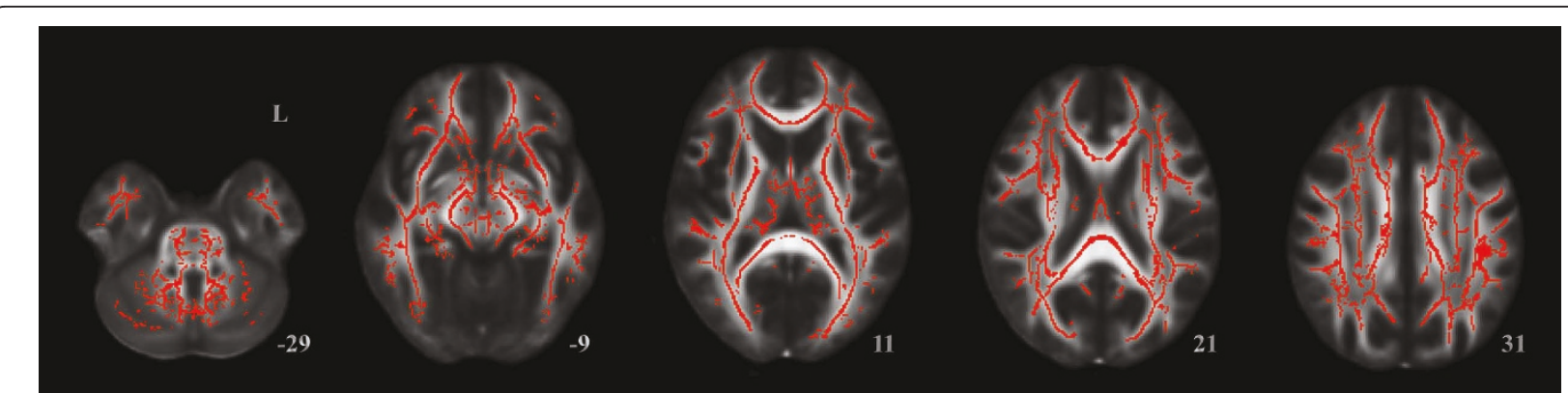

Figure 1 Results from TBSS analysis of FA maps showing the clusters of significantly reduced FA in TBI patients compared to controls in red (TFCE, $\mathbf{p}<0.05$ FWE-corrected). Widespread white matter affectation is observed.

\section{Discussion}

The present study provides evidence of the implications of TAI in declarative and working memory deficits in TBI. DTI group comparison revealed global whole brain reductions in mean FA values for patients and FA maps confirmed that almost all the major fibers were involved. Although our patients suffered global white matter integrity impairment, we found two different and restricted patterns of correlations with the FA and neuropsychological assessment. Whole brain DTI analysis showed that decreased FA throughout the brain correlated with 2-back measures but not with the Rivermead Test. Results from the ROI analyses of the main association fibers showed, as predicted, that working memory specifically correlated with the superior longitudinal fasciculi. However, it was also found to correlate with the corpus callosum, the arcuate fasciculi and with the fornix. On the other hand, declarative memory deficits only correlated with the fornix, as we had expected, and the corpus callosum. These results suggest that there are two different patterns of FA reduction related with two types of memory dysfunctions.

Table 4 Differences between groups in mean FA from the whole skeletonised brain and the ROIs

\begin{tabular}{lccccc}
\hline & $\begin{array}{c}\text { TBI } \\
\text { Mean }\end{array}$ & $\begin{array}{c}\text { group } \\
\text { SD }\end{array}$ & $\begin{array}{c}\text { Control } \\
\text { Mean }\end{array}$ & $\begin{array}{c}\text { group } \\
\text { SD }\end{array}$ & $\mathbf{t}$ ( $\boldsymbol{p}$ values $)$ \\
\hline FA global & 0.360 & 0.280 & 0.423 & 0.018 & $-7.43(<0.001)$ \\
FA CC & 0.410 & 0.460 & 0.510 & 0.024 & $-7.04(<0.001)$ \\
FA SLF & 0.364 & 0.026 & 0.421 & 0.018 & $-7.02(<0.001)$ \\
FA ILF & 0.045 & 0.003 & 0.052 & 0.002 & $-7.23(<0.001)$ \\
FA IFO & 0.390 & 0.031 & 0.456 & 0.018 & $-7.45(<0.001)$ \\
FA fornix & 0.316 & 0.030 & 0.396 & 0.022 & $-8.05(<0.001)$ \\
FA cingulum & 0.401 & 0.048 & 0.493 & 0.032 & $-6.16(<0.001)$ \\
FA arcuate & 0.373 & 0.027 & 0.430 & 0.018 & $-6.05(<0.001)$ \\
FA uncinate & 0.351 & 0.032 & 0.403 & 0.019 & $-5.34(<0.001)$ \\
\hline
\end{tabular}

TBI: Traumatic Brain Injury; FA: fractional anisotropy; CC: corpus callosum; SLF: superior longitudinal fasciculi; ILF: inferior longitudinal fasciculi; IFO: inferior fronto-occipital fasciculi.
We found that superior longitudinal fasciculi damage is related with working memory but not with declarative memory deficits. These correlations were expectable since the longitudinal fasciculi connect the associative frontal and parietal regions involved in working memory functions [70-72,49]. The correlation between working memory deficit and the superior longitudinal was also described in multiple sclerosis, pathology that also involves white matter damage [50].

In our sample, FA reductions of corpus callosum correlated with both working and declarative memory impairments. In declarative memory the correlations were seen in the posterior region whereas in working memory the correlations involved anterior and posterior regions, thus again these results point to differential patterns of correlations for both types of memory impairment.

According our results, declarative memory impairment did not depend on diffuse white matter damage since no correlations between FA maps or mean values and declarative memory values were seen. However, the ROI analysis revealed that the fornix FA impairment correlated with the Rivermead test. This result is in agreement with the role of the damage of the hippocampus and its connections in declarative memory deficits in TBI $[45,46]$.

Our declarative memory results partially agree with those obtained by Salmond et al. [30]. Using a voxelbased analysis with SPM tools, these authors found a significant positive correlation between declarative memory and diffusivity in the left hippocampal formation, the left posterior cingulate, and the left frontal, temporal and occipital regions. The more widespread pattern of correlations observed in their study can be explained by the use of FDR correction, which is more liberal than the FWE correction used in ours [73]. Correlations between FA values in the fornix and declarative memory impairment have been also observed in patients with multiple sclerosis [74]. Other studies investigating FA correlations with declarative memory 


\section{Working Memory- 2back task}

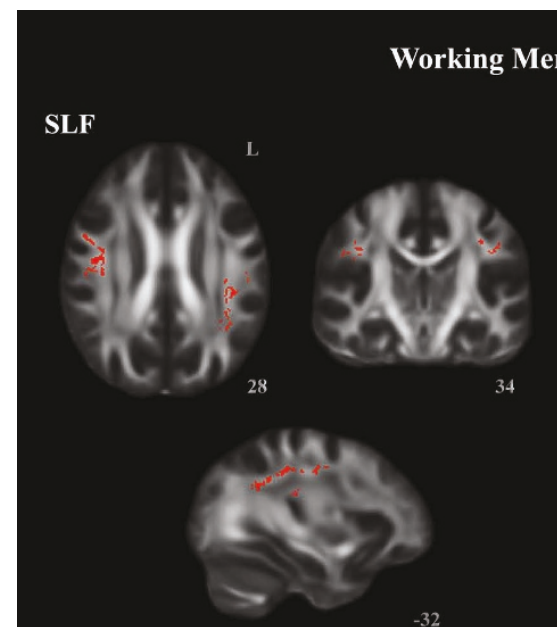

Fornix
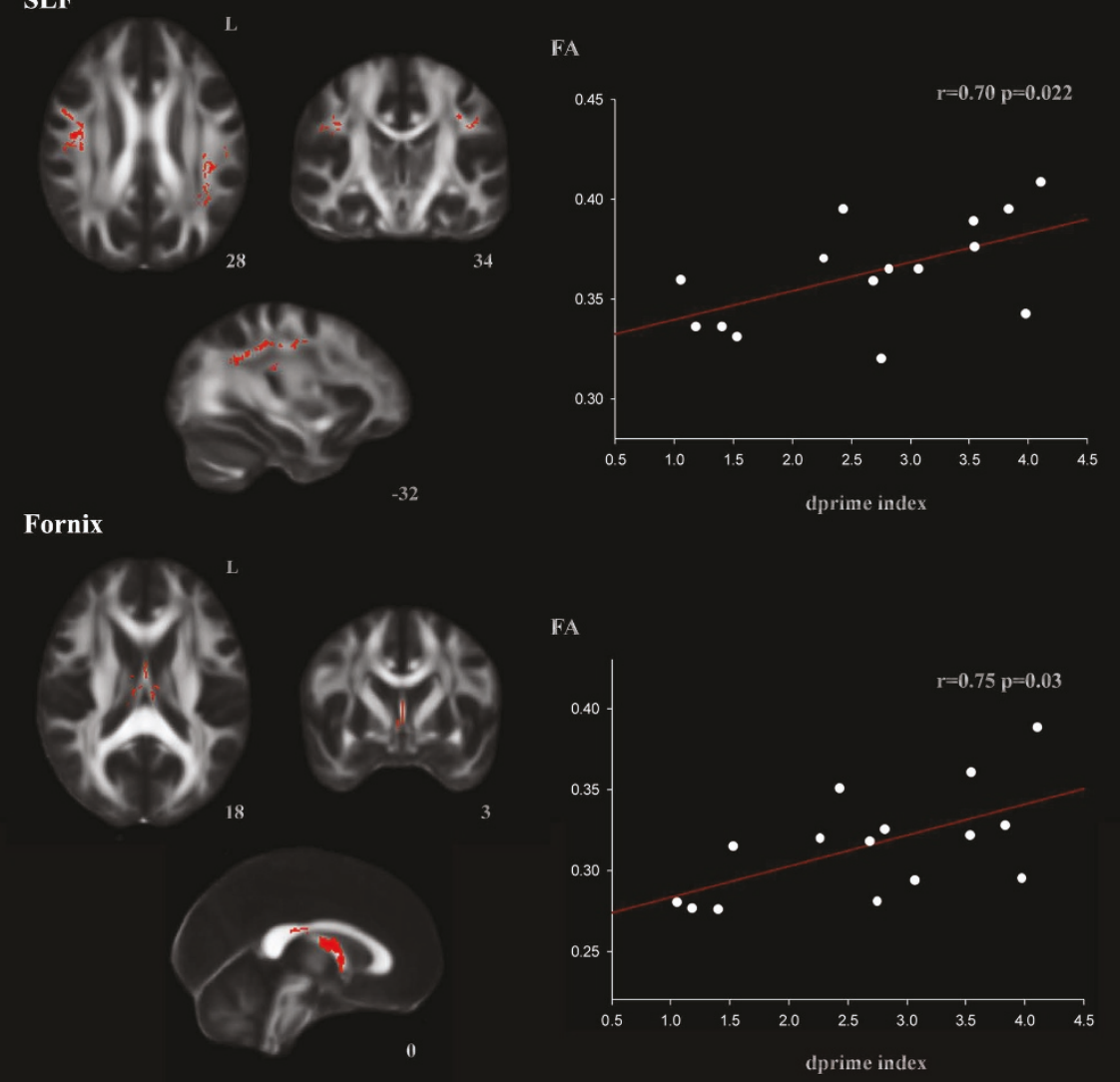

Corpus Callosum
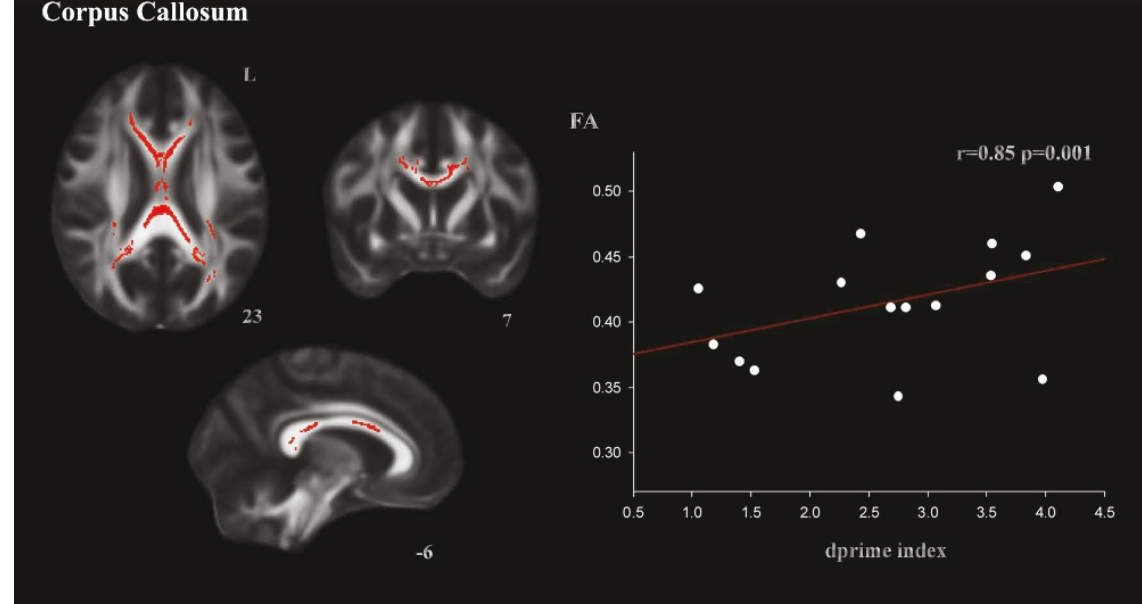

Figure 2 ROI correlations with d-prime 2-back index in the TBI group for the SLF, fornix, and corpus callosum ROIs (TFCE, $p<0.05$ FWE-corrected). Correlation coefficient ( $r$ ) was directly converted from $t$ values of the TBSS output. The $t$ and $r$ values correspond to the most statistically significant voxel for each cluster.

functions in mild TBI samples have reported significant correlations with the uncinate fasciculi $[30,32]$ and the cingulum [28]. Although we found decreased FA in these fasciculi, correlations did not reach statistical significance. These discrepancies may be explained by the varying grade of severity of the samples, the difference in the memory tests used, and DTI methodological differences.

In the present study, working memory deficits also correlated with the fornix in both the whole brain 
Table 5 TBSS results. Correlation with working and declarative memory measures in the ROls in the TBI group

\begin{tabular}{|c|c|c|c|c|c|c|}
\hline 2-back d-prime index & $\begin{array}{l}\text { Cluster } \\
\text { size }\end{array}$ & $x$ & $y$ & $z$ & $\mathrm{p}$ & $r$ \\
\hline \multirow{5}{*}{$\begin{array}{l}\text { Superior longitudinal } \\
\text { fasciculus }\end{array}$} & 908 & -38 & -49 & 22 & 0.022 & 0.70 \\
\hline & 440 & 51 & 2 & 24 & 0.025 & 0.71 \\
\hline & 91 & -29 & -7 & 39 & 0.044 & 0.67 \\
\hline & 27 & -31 & -14 & 40 & 0.045 & 0.69 \\
\hline & 20 & -46 & -46 & 23 & 0.048 & 0.69 \\
\hline \multirow[t]{4}{*}{ Arcuate fasciculus } & 121 & 50 & 3 & 27 & 0.030 & 0.75 \\
\hline & 45 & -34 & -32 & 35 & 0.044 & 0.64 \\
\hline & 30 & -38 & -49 & 23 & 0.045 & 0.73 \\
\hline & 16 & -36 & -29 & 27 & 0.048 & 0.63 \\
\hline \multirow[t]{3}{*}{ Corpus callosum } & 3310 & -7 & 14 & 22 & 0.028 & 0.65 \\
\hline & 2195 & -13 & -39 & 23 & 0.021 & 0.77 \\
\hline & 211 & -32 & -41 & 16 & 0.043 & 0.67 \\
\hline Fornix & 1206 & -9 & -14 & 13 & 0.001 & 0.85 \\
\hline$\underline{\text { RBMT }}$ & $\begin{array}{l}\text { Cluster } \\
\text { size }\end{array}$ & $x$ & $y$ & $z$ & $\mathrm{p}$ & $r$ \\
\hline \multirow[t]{2}{*}{ Corpus callosum } & 1008 & -16 & -40 & 27 & 0.033 & 0,71 \\
\hline & 538 & 7 & -12 & 25 & 0.042 & 0.68 \\
\hline \multirow[t]{2}{*}{ Fornix } & 140 & -2 & -12 & -24 & 0.034 & 0,54 \\
\hline & 68 & 1 & 5 & -4 & 0.042 & 0.60 \\
\hline
\end{tabular}

All regions identified at family wise error corrected $p<0.05$ with a cluster size of at least 10 voxels. Coordinates are given at peak voxel coordinate in MNI152 standard space.

analysis and the ROI analyses. There is some evidence from fMRI studies that the hippocampus is involved in working memory functions in healthy subjects [75-78]. Moreover, several animal studies also suggest a role for the hippocampus in working memory [79-81]. Anatomically, prefrontal regions involved in working memory tasks receive projections from the hippocampus $[82,83]$ and are connected directly to the ventral hippocampus and indirectly to the dorsal hippocampus via the thalamus [84-86]. This structural connectivity supports the idea that the hippocampus has a role in working memory functioning as suggested by our findings.

Finally, significant correlations were observed between the PTA variable and white matter integrity. Whole brain map analysis showed that PTA is an excellent index predictor of the degree of impairment of the major white matter tracts and association fibers. These results suggest that the recovery of memory functions is dependent on the integrity of the complex neocortical regions. Unlike previous studies $[13,14,17]$, no correlations were found between GCS and FA maps or mean FA values. This result was to be expected as the fact that all our patients had severe TBI meant that GCS variability would not be sufficient to reach statistical significance.

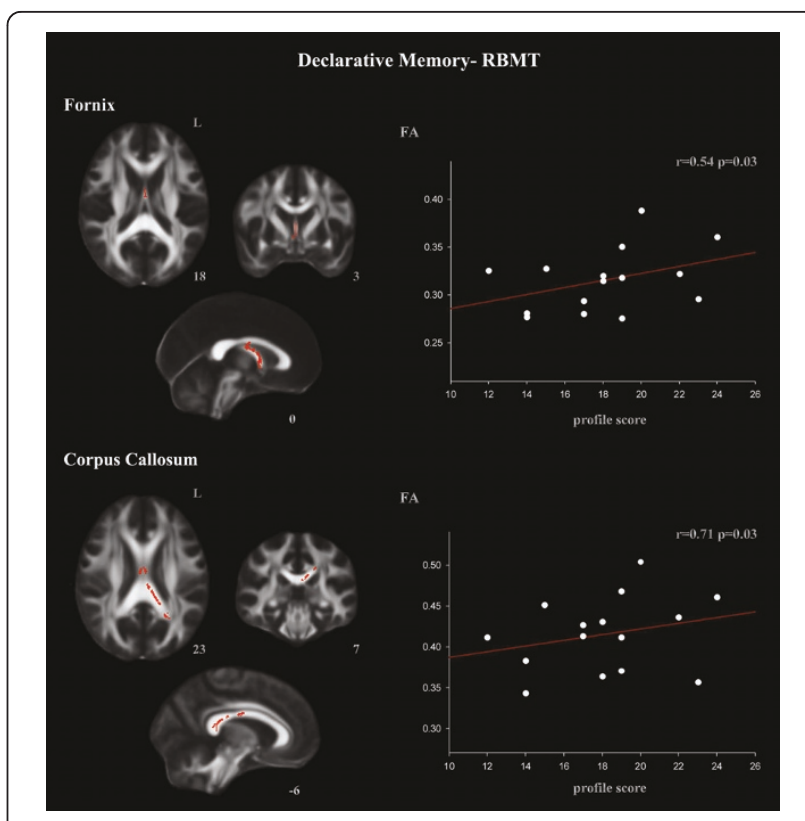

Figure 3 ROI correlations with RBMT in the TBI group: RBMT correlated with the fornix and the corpus callosum ROIs (TFCE, $\mathbf{p}<0.05$ FWE-corrected). Correlation coefficient ( $r$ ) was directly converted from $t$ values of the TBSS output. The $t$ and $r$ values correspond to the most statistically significant voxel for each cluster.

Our study has certain limitations and our results should be regarded as preliminary. The small sample size and its specific diffuse characteristics may preclude the generalization of the results. The presence of mixed focal and diffuse pathology frequently observed in severe TBI may confound the mapping of neural and behavioral changes in these patients. As our study sample excluded significant cortical pathology, the cognitive impairment observed is more likely to be due to the diffuse pathology alone. Nevertheless, we cannot exclude the possibility that reductions in gray matter in several subcortical structures are also influencing memory deficits in TBI.

\section{Conclusions}

This DTI study suggests that declarative and working memory deficits in diffuse TBI patients are related to differential patterns of FA reduction. Working memory impairment reflects the diffuse white matter damage affecting large scale networks such as the superior longitudinal fasciculi, whereas declarative memory deficits seem to be the result of more local disruption of the cerebral circuitry.

\section{Acknowledgements}

This work was supported by a grant from the Spanish Ministry of Science and Innovation (SAF2007-66077) and a grant from the Generalitat de Catalunya (2009SGR941) to the Neuropsychology Research Group. Eva M. 
Palacios was supported by a fellowship from the Institute of Biomedical Research August Pi i Sunyer (IDIBAPS) (89000313). Davinia Fernandez-Espejo was supported by a fellowship from the Spanish Ministry for Education (AP2006-00862).

\section{Author details}

'Department of Psychiatry and Clinical Psychobiology, University of Barcelona, Barcelona, Spain. ${ }^{2}$ Institute of Biomedical Research August Pi i Sunyer (IDIBAPS), Barcelona, Spain. ${ }^{3}$ Department of Neuropsychology, Institut Universitari de Neurorehabilitació Guttmann, Badalona, Spain. ${ }^{4}$ Centre de Diagnòstic per la Imatge Hospital Clínic de Barcelona (CDIC), Hospital Clínic de Barcelona, Spain

\section{Authors' contributions}

EP, DFE and CJ made substantial contribution to conception and design, interpretation of data, drafting and writing of manuscript and further revisions of the manuscript. Neuroimaging data were analyzed by EP and DFE. Neuroimaging sequence acquisitions, neurological description and classification of data by NB. RSC and TR participated in the collection of neuropsychological data and in the collection of acute clinical data. JT and PV made a critical revision of the manuscript for important intellectual content providing additional comments and contributions. CJ supervised the study. All authors read and approved the final manuscript.

\section{Competing interests}

The authors declare that they have no competing interests.

Received: 13 October 2010 Accepted: 23 February 2011

Published: 23 February 2011

\section{References}

1. Adams JH, Graham DI, Murray LS, Scott G: Diffuse axonal injury due to non missile head injury in humans: An analysis of 45 cases. Ann Neurol 1982, 12:557-563.

2. Gennarelli TA, Thibault LE, Adams JH, Graham DI, Thompson CJ, Marcincin RP: Diffuse axonal injury and traumatic coma in the primate. Ann Neurol 1982, 12:564-574.

3. Povlishock JT, Katz DI: Update of neuropathology and neurological recovery after traumatic brain injury. J Head Trauma Rehabil 2005, 20:76-94.

4. Buki A, Povlishock JT: All roads lead to disconnection?-Traumatic axonal injury revisited. Acta Neurochir 2006, 148:181-94.

5. Scheid R, Walther K, Guthke T, Preul C, von Cramon DY: Cognitive sequelae of diffuse axonal injury. Arch Neurol 2006, 63:418-424.

6. Rugg-Gunn FJ, Symms MR, Barker GJ, Greenwood R, Duncan JS: Diffusion imaging shows abnormalities after blunt head trauma when conventional magnetic resonance imaging is normal. J Neurol Neurosurg Psychiatry 2001, 70:530-533.

7. Rutgers DR, Fillard P, Paradot G, Tadie M, Lasjaunias P, Ducreux D: Diffusion tensor imaging characteristics of the corpus callosum in mild, moderate, and severe traumatic brain injury. AJNR Am J Neuroradiol 2008, 29:1730-1735.

8. Miles L, Grossman Rl, Johnson G, Babb JS, Diller L, Inglese M: Short-term DTI predictors of cognitive dysfunction in mild traumatic brain injury. Brain Inj 2008, 22:115-22.

9. Le Bihan D: Looking into the functional architecture of the brain with diffusion MRI. Nat Rev Neurosci 2003, 4:469-480.

10. Chenevert TL, Brunberg JA, Pipe JG: Anisotropic diffusion in human white matter: Demonstration with MR techniques in vivo. Radiology 1990, 177:401-405

11. Beaulieu C: The basis of anisotropic water diffusion in the nervous system - a technical review. NMR in Biomed 2002, 15:435-455.

12. Ciccarelli O, Catani M, Johansen-Berg H, Clark C, Thompson A: Diffusionbased tractography in neurological disorders: Concepts, applications, and future developments. Lancet Neurol 2008, 7:715-727.

13. Huisman TA, Schwamm LH, Schaefer PW, Koroshetz WJ, Shetty-Alva N, Ozsunar Y, Wu O, Sorensen AG: Diffusion tensor imaging as potential biomarker of white matter injury in diffuse axonal injury. AJNR Am J Neuroradiol 2004, 25:370-376.

14. Benson RR, Meda SA, Vasudevan S, Kou Z, Govindarajan KA, Hanks RA, Millis SR, Makki M, Latif Z, Coplin W, Meythaler EJ, Haacke M: Global white matter analysis of diffusion tensor images is predictive of injury severity in traumatic brain injury. J Neurotrauma 2007, 24:446-459.

15. Wilde EA, Chu Z, Bigler ED, Hunter JV, Fearing MA, Hanten G, Newsome MR, Scheibel RS, Li X, Levin HS: Diffusion tensor imaging in the corpus callosum in children after moderate to severe traumatic brain injury. J Neurotrauma 2006, 23:1412-1426

16. Sidaros A, Engberg AW, Sidaros K, Liptrot MG, Herning M, Petersen P, Paulson OB, Jernigan TL, Rostrup E: Diffusion tensor imaging during recovery from severe traumatic brain injury and relation to clinical outcome: A longitudinal study. Brain 2008, 131:559-572.

17. Bendlin BB, Ries ML, Lazar M, Alexander AL, Dempsey RJ, Rowley HA, Sherman JE, Johnson SC: Longitudinal changes in patients with traumatic brain injury assessed with diffusion-tensor and volumetric imaging. Neuroimage 2008, 42:503-514.

18. Kumar R, Husain M, Gupta RK, Hasan KM, Haris M, Agarwal AK, Pandey CM, Narayana PA: Serial changes in the white matter diffusion tensor imaging metrics in moderate traumatic brain injury and correlation with neuro-cognitive function. J Neurotrauma 2009, 26:1-16.

19. Arfanakis K, Haughton VM, Carew JD, Rogers BP, Dempsey RJ Meyerand ME: Diffusion tensor MR imaging in diffuse axonal injury. AJNR Am J Neuroradiol 2002, 23:794-802.

20. Inglese M, Makani S, Johnson G, Cohen BA, Silver JA, Gonen O, Grossman Rl: Diffuse axonal injury in mild traumatic brain injury: A diffusion tensor imaging study. J Neurosurg 2005, 103:298-303.

21. Bazarian JJ, Zhong J, Blyth B, Kavcic V, Peterson D: Diffusion tensor imaging detects clinically important axonal damage after mild traumatic brain injury: A pilot study. J Neurotrauma 2007, 24:1447-1459.

22. Lipton ML, Gellella E, Lo C, Gold T, Ardekani BA, Shifteh K, Bello JA, Branch CA: Multifocal white matter ultrastructural abnormalities in mild traumatic brain injury with cognitive disability: A voxel-wise analysis of diffusion tensor imaging. J Neurotrauma 2008, 25:1335-1342.

23. Niogi SN, Mukherjee P, Ghajar J, Johnson C, Kolster RA, Sarkar R, Lee H, Meeker M, Zimmerman RD, Manley GT, McCandliss BD: Extent of microstructural white matter injury in postconcussive syndrome correlates with impaired cognitive reaction time: A $3 \mathrm{~T}$ diffusion tensor imaging study of mild traumatic brain injury. AJNR Am J Neuroradiol 2008, 29:967-973.

24. Wilde EA, McCauley SR, Hunter JV, Bigler ED, Chu Z, Wang ZJ, Hanten GR, Troyanskaya M, Yallampalli R, Li X, Chia J, Levin HS: Diffusion tensor imaging of acute mild traumatic brain injury in adolescents. Neurology 2008, 70:948-955.

25. Wozniak JR, Krach L, Ward E, Mueller BA, Muetzel R, Schnoebelen S, Kiragu A, Lim KO: Neurocognitive and neuroimaging correlates of pediatric traumatic brain injury: A diffusion tensor imaging (DTI) study. Arch Clin Neuropsychol 2007, 22:555-568.

26. Ewing-Cobbs L, Prasad MR, Swank P, Kramer L, Cox CS Jr, Fletcher JM Barnes M, Zhang X, Hasan KM: Arrested development and disrupted callosal microstructure following pediatric traumatic brain injury: Relation to neurobehavioral outcomes. Neuroimage 2008, 42:1305-1315.

27. Levin HS, Wilde EA, Chu Z, Yallampalli R, Hanten GR, Li X, Chia J, Vasquez AC, Hunter JV: Diffusion tensor imaging in relation to cognitive and functional outcome of traumatic brain injury in children. J Head Trauma Rehabil 2008, 23:197-208.

28. Wu TC, Wilde EA, Bigler ED, Yallampalli R, McCauley SR, Troyanskaya M, Chu Z, Li X, Hanten G, Hunter JV, Levin HS: Evaluating the relationship between memory functioning and cingulum bundles in acute mild traumatic brain injury using diffusion tensor imaging. J Neurotrauma 2010, 27:303-7.

29. Nakayama N, Okumura A, Shinoda J, Yasokawa YT, Miwa K, Yoshimura SI, Iwama T: Evidence for white matter disruption in traumatic brain injury without macroscopic lesions. J Neurol Neurosurg Psychiatry 2006, 77:850-855.

30. Salmond CH, Menon DK, Chatfield DA, Williams GB, Pena A, Sahakian BJ, Pickard JD: Diffusion tensor imaging in chronic head injury survivors: Correlations with learning and memory indices. Neurolmage 2006 29:117-124.

31. Kraus MF, Susmaras T, Caughlin BP, Walker CJ, Sweeney JA, Little DM: White matter integrity and cognition in chronic traumatic brain injury: A diffusion tensor imaging study. Brain 2007, 130:2508-2519.

32. Niogi SN, Mukheriee P, Ghajar J, Johnson CE, Kolster R, Lee H, Suh M, Zimmerma RD, Manley GT, McCandliss BD: Structural dissociation of 
attentional control and memory in adults with and without mild traumatic brain injury. Brain 2008, 131:3209-3221.

33. Lipton ML, Gellella E, Lo C, Gold T, Ardekani BA, Shifteh K, Bello JA, Branch CA: Multifocal white matter ultrastructural abnormalities in mild traumatic brain injury with cognitive disability: A voxel-wise analysis of diffusion tensor imaging. J Neurotrauma 2008, 25:1335-1342.

34. Miles L, Grossman Rl, Johnson G, Babb JS, Diller L, Inglese M: Short-term DTI predictors of cognitive dysfunction in mild traumatic brain injury. Brain Inj 2008, 22:115-22

35. Levin HS, Goldstein FC, High WM Jr, Eisenberg HM: Disproportionately severe memory deficit in relation to normal intellectual functioning after closed head injury. J Neurol Neurosurg Psychiatry 1988, 51:1294-1301.

36. Bigler ED: Lesions in traumatic brain injury: implications for clinical neuropsychology. Arch Clin Neuropsychol 2001, 16:95-131.

37. Vakil $E$ : The effect of moderate to severe traumatic brain injury (TBI) on different aspects of memory: A selective review. J Clin Exp Neuropsychol 2005, 27:977-1021.

38. Squire LR: Memory systems of the brain: A brief history and current perspective. Neurobiol Learn Mem 2004, 82:171-177.

39. Squire LR, Stark CE, Clark RE: The medial temporal lobe. Annu Rev Neurosci 2004, 27:279-306.

40. Levin HS: Memory deficit after closed-head injury. J Clin Exp Neuropsychol 1990, 12:129-153.

41. Wilson B: Recovery and compensatory strategies in head injured memory impaired people several years after insult. J Neurol Neurosurg Psychiatry 1992, 55:177-180.

42. Zec RF, Zellers D, Belman J, Miller J, Matthews J, Ferneau-Belman D, Robbs R: Long-term consequences of severe closed head injury on episodic memory. J Clin Exp Neuropsychol 2001, 23:671-691.

43. Squire LR, Zola-Morgan S: The medial temporal lobe memory system. Science 1991, 253:1380-1386.

44. Eichenbaum H: Hippocampus: Cognitive processes and neural representations that underlie declarative memory. Neuron 2004, 44:109-120.

45. Serra-Grabulosa JM, Junque C, Verger K, Salgado-Pineda P, Maneru C, Mercader JM: Cerebral correlates of declarative memory dysfunctions in early traumatic brain injury. J Neurol Neurosurg Psychiatry 2005, 76:129-131.

46. Ariza M, Pueyo R, Junque C, Mataro M, Poca MA, Mena MP, Sahuquillo J: Differences in visual vs. verbal memory impairments as a result of focal temporal lobe damage in patients with traumatic brain injury. Brain Inj 2006, 20:1053-1059.

47. Gale SD, Burr RB, Bigler ED, Blatter D: Fornix degeneration and memory in traumatic brain injury. Brain Res Bull 1993, 32:345-349.

48. Baddeley A: Working memory. Science 1992, 255:556-559.

49. Owen AM, McMillan KM, Laird AR, Bullmore E: N-back working memory paradigm: A meta-analysis of normative functional neuroimaging studies. HumBrain Mapp 2005, 25:46-59.

50. Bonzano L, Pardini M, Mancardi GL, Pizzorno M, Roccatagliata L: Structural connectivity influences brain activation during PVSAT in multiple sclerosis. Neuroimage 2009, 44:9-15

51. Gong G, He Y, Concha L, Lebel C, Gross DW, Evans AC, Beaulieu C: Mapping anatomical connectivity patterns of human cerebral cortex using in vivo diffusion tensor imaging tractography. Cereb Cortex 2009, 19:524-39.

52. Levin HS, O'Donnell VM, Grossman RG: The Galveston Orientation and Amnesia Test. A practical scale to assess cognition after head injury. J Nerv Ment Dis 1979, 167:675-684.

53. Wechsler D: Escala de intenteligencia de Wechsler para adultos (WAIS-III). Madrid: TEA Ediciones; 1999.

54. Lezak MD, Howieson DB, Loring DD, Hannay HJ, Fisher JS: Neuropsychological Assessment. New York: Oxford University Press; 2004.

55. Cohen JD, Perlstein WM, Braver TS, Nystrom LE, Noll DC, Jonides J, Smith EE: Temporal dynamics of brain activation during a working memory task. Nature 1997, 386:604-608.

56. Wilson B, Cockburn J, Baddeley AD: The Rivermead Behavioural Memory Test. Bury St. Edmunds, UK: Thames Valley Test; 1991.

57. Wills $P$, Clare L, Shiel A, Wilson BA: Assessing subtle memory impairments in the everyday memory performance of brain injured people: exploring the potential of the extended Rivermead Behavioural Memory Test. Brain Inj 2000, 14:693-704.
58. Smith SM: Fast robust automated brain extraction. Hum Brain Mapp 2002, 17:143-155.

59. Behrens TE, Woolrich MW, Jenkinson M, Johansen-Berg H, Nunes RG, Clare S, Matthews PM, Brady JM, Smith SM: Characterization and propagation of uncertainty in diffusion-weighted MR imaging. Magn Reson Med 2003, 50:1077-1088.

60. Smith SM, Jenkinson M, Johansen-Berg H, Rueckert D, Nichols TE, Mackay CE, Watkins KE, Ciccarelli O, Cader MZ, Matthews PM, Behrens TEJ: Tract-based spatial statistics: Voxelwise analysis of multi-subject diffusion data. Neuroimage 2006, 31:1487-1505.

61. Jones DK, Symms MR, Cercignani M, Howard RJ: The effect of filter size on VBM analyses of DT-MRI data. Neuroimage 2005, 26:546-554.

62. Nichols TE, Holmes AP: Nonparametric Permutation Tests for Functional Neuroimaging: A Primer with Examples. Hum Brain Mapp 2002, 15:1-25.

63. Hayasaka S, Nichols TE: Validating cluster size inference: random field and permutation methods. Neuroimage 2003, 20:2343-2356.

64. Smith SM, Nichols TE: Threshold-free cluster enhancement: addressing problems of smoothing, threshold dependence and localization in cluster inference. Neuroimage 2009, 44:83-98.

65. Toga AW, Thompson PM, Mori S, Amunts K, Zilles K: Towards multimodal atlases of the human brain. Nat Rev Neurosci 2006, 7:952-966.

66. Eickhoff SB, Paus T, Caspers S, Grosbras MH, Evans AC, Zilles K, Amunts K: Assignment of functional activations to probabilistic cytoarchitectonic areas revisited. Neuroimage 2007, 36:511-521.

67. Mori S, Wakana S, Peter CM, Van Zijl PCM: MRI Atlas of Human White Matter. Amsterdam, The Netherlands: Elsevier; 2005.

68. Wakana S, Caprihan A, Panzenboeck MM, Fallon JH, Perry M, Gollub RL, Hua K, Zhang J, Jiang H, Dubey P, Blitz A, van Zijl P, Mori S: Reproducibility of quantitative tractography methods applied to cerebral white matter. Neuroimage 2007, 36:630-644.

69. Hua K, Zhang J, Wakana S, Jiang H, Li X, Reich DS, Calabresi PA, Pekar JJ, van Zijl PC, Mori S: Tract probability maps in stereotaxic spaces: analysis of white matter anatomy and tract-specific quantification. Neuroimage 2008, 39:336-47.

70. Klingberg T, O'Sullivan BT, Roland PE: Bilateral activation of fronto-parietal networks by incrementing demand in a working memory task. Cereb Cortex 1997, 7:465-471.

71. Jonides J, Schumacher EH, Smith EE, Koeppe RA, Awh E, Reuter-Lorenz PA, Marshuetz C, Willis CR: The role of parietal cortex in verbal working memory. J Neurosci 1998, 18:5026-5034.

72. Olesen PJ, Westerberg H, Klingberg T: Increased prefrontal and parietal activity after training of working memory. Nat Neurosci 2004, 7:75-79.

73. Chumbley JR, Friston KJ: False discovery rate revisited: FDR and topological inference using gaussian random fields. Neuroimage 2009, 44:62-70.

74. Dineen RA, Vilisaar J, Hlinka J, Bradshaw CM, Morgan PS, Constantinescu CS, Auer DP: Disconnection as mechanism for cognitive dysfunction in multiple sclerosis. Brain 2009, 132:239-249.

75. Ranganath C, D'Esposito M: Medial temporal lobe activity associated with active maintenance of novel information. Neuron 2001, 31:865-873.

76. Cabeza R, Dolcos F, Graham R, Nyberg L: Similarities and differences in the neural correlates of episodic memory retrieval and working memory. Neuroimage 2002, 16:317-330.

77. Davachi L, Wagner AD: Hippocampal contributions to episodic encoding: Insights from relational and item-based learning. J Neurophysiol 2002, 88:982-990.

78. Rissman J, Gazzaley A, D'Esposito M: Dynamic adjustments in prefrontal, hippocampal and inferior temporal interactions with increasing visual working memory load. Cereb Cortex 2008, 18:1618-1629.

79. Lee I, Kesner RP: Time-dependent relationship between the dorsal hippocampus and the prefrontal cortex in spatial memory. J Neurosci 2003, 23:1517-1523.

80. Izaki Y, Takita M, Akema T: Specific role of the posterior dorsal hippocampus-prefrontal cortex in short-term working memory. Eur $J$ Neurosci 2008, 27:3029-3034.

81. Yoon T, Okada J, Jung MW, Kim JJ: Prefrontal cortex and hippocampus subserve different components of working memory in rats. Learn Mem 2008, 15:97-105.

82. Rosene DL, Van Hoesen GW: Hippocampal efferents reach widespread areas of cerebral cortex and amygdala in the rhesus monkey. Science 1977, 198:315-317. 
83. Barbas H, Blatt GJ: Topographically specific hippocampal projections target functionally distinct prefrontal areas in the rhesus monkey. Hippocampus 1995, 5:511-533.

84. Ferino F, Thierry AM, Glowinski J: Anatomical and electrophysiological evidence for a direct projection from ammon's horn to the medial prefrontal cortex in the rat. Brain Res 1987, 65:421-426.

85. Laroche S, Davis S, Jay TM: Plasticity at hippocampal to prefrontal cortex synapses: Dual roles in working memory and consolidation. Hippocampus 2000, 10:438-446.

86. Thierry AM, Gioanni Y, Degenetais E, Glowinski J: Hippocampo-prefrontal cortex pathway: Anatomical and elecctrophysiological characteristics. Hippocampus 2000, 10:411-419.

\section{Pre-publication history}

The pre-publication history for this paper can be accessed here: http://www.biomedcentral.com/1471-2377/11/24/prepub

doi:10.1186/1471-2377-11-24

Cite this article as: Palacios et al:: Diffusion tensor imaging differences relate to memory deficits in diffuse traumatic brain injury. $B M C$ Neurology 2011 11:24.

\section{Submit your next manuscript to BioMed Central} and take full advantage of:

- Convenient online submission

- Thorough peer review

- No space constraints or color figure charges

- Immediate publication on acceptance

- Inclusion in PubMed, CAS, Scopus and Google Scholar

- Research which is freely available for redistribution

Submit your manuscript at www.biomedcentral.com/submit
C Biomed Central 